\title{
Managing Indigenous Minority Groups in the Tourism Industry: An Exploratory Case Study in Southern Laos
}

\author{
Hiroshi Kuwahara ${ }^{1}$ \\ ${ }^{1}$ Faculty of Industrial Management and Tourism Sciences, University of the Ryukyus, Nishihara-cho, \\ Okinawa, Japan
}

\begin{abstract}
Tourism-based employment has been promoted for reducing poverty in the least developed countries (LDCs). However, for employing the poor sustainably, particularly, indigenous minority groups, management has to cope with the socioeconomic disadvantages in these environments. This study aims to explore the challenges and practical strategies for human resource management (HRM) of indigenous minority groups in the tourism sectors of LDCs; specifically, those identified as "best practice" in southern Laos. Semi-structured interviews were conducted with the managing director of the project regarding training, compatibility with family life, benefits and incentives, and leadership and teamwork. A qualitative analysis was applied to the interview data and hypothetical HRM strategies were derived. Then, to examine the validity of these strategies within the project, semi-structured interviews were conducted with a half of the employees. The results suggest significance for the following HRM strategies: a social orientation toward tourism industry hygiene standards; a flexible leave system that allows employees to participate in family events and family-operated farming; and nonfinancial benefits such as food, clothing, and housing.
\end{abstract}

\section{Background and Purpose of Study}

The need to eradicate poverty in the least developed countries (LDCs) has been recognized by the international community [1]. The role of the tourism industry in reducing poverty in LDCs has been emphasized recently by international organizations such as the United Nations World Tourism Organization [2] and the International Labour Organization [3]. In their policies, the employment of the poor in the tourism industry is considered to be one of the most direct and effective mechanisms to reduce poverty in LDCs [4]. Therefore, the tourism industry can contribute to poverty eradication in LDCs substantially if it can expand sustainable employment of the poor.

However, the sustainable employment of the indigenous poor in the tourism industries of LDCs creates unique challenges for employers, which do not arise in economically developed countries. LDCs are mainly agrarian countries and most of the poor are traditional farmers, with little knowledge and few skills useful for the tourism industry. Furthermore, the training and development of tourism industry staff are not well-established, and the poor have limited access to training and educational systems economically, even if infrastructure exists in their country. Therefore, if companies and organizations plan to employ these groups in the tourism industry, then they must adopt HRM strategies that address this unique situation. This study specifically examines the HRM strategies in the tourism industry of the Lao People's Democratic Republic (Laos). 
The majority of supporters for tourism-based employment initiatives (aimed at the poor) in developing countries, including the LDCs, have focused on so-called community-based tourism (CBT) [5]. In fact, many CBTs have been initiated by NGOs and development agencies [6]. Till date, few such projects led by private enterprises in LDCs have been reported in academic publications. This may be because the role of private tourism enterprises in poverty eradication has been evaluated modestly [7].

However, many NGOs and development agencies are working on projects with limited periods of support. They have often faced the challenge of supporting projects until they became autonomous or sustainable. Conversely, tourism projects initiated by private enterprises aim at seeking both shortand long-term economic returns; therefore, those projects need HRM strategies for creating sustainable business. In economically developed countries, a core of private enterprises comprises the tourism industry. Therefore, even in LDCs, private enterprises need to take an active role in developing the tourism industry. The significance of private enterprise involvement in developing the tourism industry in LDCs is comparable with those of NGOs and development agencies.

The majority of the poor in the LDCs live in geographically remote and rural areas [2], which is regarded a disadvantage for employers [8]. However, geographically remote areas often provide venues of unspoiled, scenic, or historic value, which can represent high potential as tourist attractions, particularly in the age of globalization. Thus, for entrepreneurs who want to develop a new tourism business, remote areas of LDCs with scenic wonders would be realistic places to consider. Then, for those entrepreneurs, HRM strategies to employ local people would be key factors in developing a sustainable business plan. In addition, for policy makers of LDCs who look for opportunities to utilize tourism for poverty eradication, effective HRM strategies for sustainable tourism employment of the poor are vital tools to invite private entrepreneurs establishing businesses in rural regions.

As stated above, studies of tourism projects in LDCs initiated by private enterprises are limited in academic publications so far. In particular, case studies on HRM are hardly reported, regardless of their importance. This study focused on a single tourism project initiated and managed by a private entrepreneur in Laos. This project has employed staff from indigenous minority groups for more than 10 years in the poor southern region of Laos, where the poverty rate of indigenous people is estimated much higher than that of nonindigenous inhabitants [9].

This case study assumed this project to be a rare example of "best practice" tourism HRM in a LDC. The purpose of this study was to explore HRM practices qualitatively and to propose hypothetical HRM strategies applicable for sustainable tourism employment of the poor in Southeast Asia's LDCs, including Laos.

\section{Methods}

\subsection{Research Strategy}

The HRM strategies applicable for sustainable tourism employment of the poor should achieve a good balance between capacity building of the poor in LDCs, with consideration toward their unique socioeconomic background, and the commercial return expected by satisfying customers, most of whom reside in non-LDCs. To explore HRM in such a complex context, the case study method was used because it allows researchers to understand HRM deeply and multilaterally [10]. In addition, when a case is considered to be rare in a research domain, a single case study is worth enough to identify hypotheses inductively [11]. Thus, this study chose the following project only as a unit of analysis.

\subsubsection{Unit of analysis: Uttayan Bajiang project}

The unit of analysis was a tourism project entitled Uttayan Bajiang, which is located in the midland forest area of Champasak province, Laos. Project development began in 1996 and construction began in 1999, with the first visitors welcomed in December, 2003. The total area of the project grounds is 
217 ha, and $90 \%$ of the property is covered by trees and plants. The biggest attractions are two waterfalls. A small ethnic village is also open to visitors. A restaurant and bungalows with a view are commercially operated. As of March 2013, about 60 people from 13 indigenous minority groups in Laos, ethnically classified as Mon-Khmer-speaking groups, are working at the project. Before they were employed by the project, they had been practicing lifestyle of subsistence farming, hunting, and collecting forest products according to the managing director of the project. He writes about initially employed works, "Workers came to work with fishing equipments for catching fish and catapults for shooting birds. Even there was only one single bird singing while workers were working, they would stop and immediately aimed their catapult at that singing and unfortunate animal. They did not have food to eat during lunch break. Thus, some want for fishing during lunch time. Some lie square on the ground and let their co-workers cut or chop their long hair with knife; they did not have any scissors or hair clippers" [12]. About half of the employees are illiterate about the Lao language, the single recognized national language of Laos, although all of them can speak it. These staffs work as cooks, waitresses/waiters, housekeepers, gardeners, maintenance staff, in-house tour guides, and other positions within the ethnic village. The project was initiated and has been managed by a Thai entrepreneur, the managing director of the project, who has managed restaurants in Thailand and Germany for more than 20 years. Visitors are mainly group tours from Thailand, followed by tourists from various developed countries.

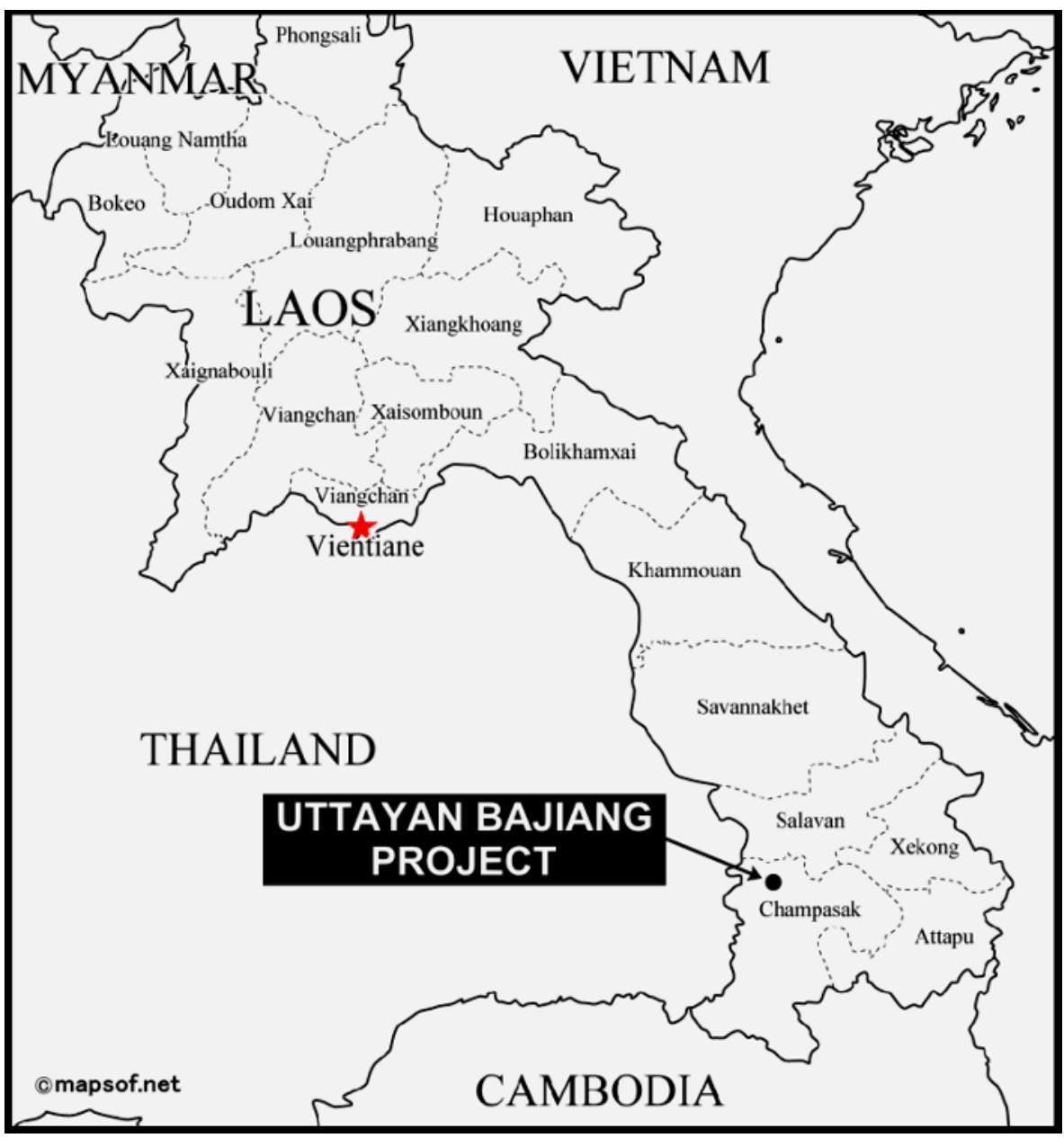

Figure 1. Location of the Uttayan Bajiang project. 


\subsection{Research Design and Methods}

This case study consists of the following three phases of semi-structured interviews with the managing director and employees, and the subsequent qualitative analysis. The author of this paper has interviewed the managing director (in English) almost annually from 2007 to 2014. In March 2013, with the aid a professional Lao-Japanese interpreter, the author also interviewed employees.

Phase I: Preliminary interviews with the managing director. As one might approach a new puzzle, the open-ended semi-structured interviews were conducted to explore strategically salient domains of HRM when employing poor ethnic minorities. These open questions were with comprehensive HRM keywords used in the hospitality industry within economically developed countries [13, 14]. Consequently, the following first-order domains of HRM were derived, i.e., training and development, compatibility with family life, benefits and incentives, and leadership and teamwork.

Phase II: Main interviews with the managing director. Semi-structured interviews were conducted to explore HRM strategies intensively in each of the four HRM domains derived in Phase I. To clarify and deepen understanding of his HRM strategy in the each domain, probing questions as well as open-ended questions were presented.

Phase III: Interviews with the employees. To examine the practical validity of these HRM strategies within the project, semi-structured interviews were conducted with 30 employees, mostly in small groups of two or three employees. The reason why interviews were not conducted individually was that Lao indigenous minority groups rarely express individual attitudes and opinions to outsiders; indeed, this is a fearful practice for them [15]. The employee cohort is summarized as follows: the median of age was 22 years, the sample was $63 \%$ male, the median of length of employment was 7 years, and more than half of the interviewees had never entered a junior high school. The interview questions were developed to qualitatively explore their attitudes toward specific HRM activities identified in Phase II. Questions about some HRM strategies (e.g., tipping policies and pay advances) were excluded because they might seriously harm the open attitude of employees toward the interview as a whole.

\section{Findings of the Study}

The following sub-sections describe the key HRM strategies derived from interviews with the managing director of the project. These HRM strategies were emphasized during the interviews and/or repeated in the context of the employees' socio-economic backgrounds. In other words, they would be important and effective HRM strategies, especially from the viewpoint of sustainable tourism employment of the poor minority groups in LDCs. The items indicated by boldface were also positively supported qualitatively by responses from the employee interviews.

\subsection{Training and development}

At the very beginning of their employment, and to ensure that all employees satisfy sanitary standards expected in the hospitality business, cultural orientation must be provided, without exception. Specifically, the orientation includes basic sanitary customs such as ways of washing one's hands and body, using the toilet, and brushing teeth. Good hygiene is an essential requirement for the hospitality business. With strict social orientation, employees come to understand that these customs are important for their health as well as for business. Employees need to learn how to smile at customers as an initial nonverbal communication. This is because it is not usual for them to smile at outsiders when they are living in their villages. Employees must constantly practice basic English verbal expressions for customer services from the beginning of employment. Even short English conversations with foreign customers reduce their fear of outsiders. 


\subsection{Compatibility With Family Life}

Employees should be allowed a flexible leave schedule, in accordance to the needs of their familyoperated farms and family events, which are essential parts of life. Employees should be hired from different villages to mitigate conflicting availability when employees from the same village take leave at the same time. Pay advances in the form of food (rice) should be available. Although all employees are fed everyday by the project, their home food situations vary from family to family. With a flexible system of payment to support their families, employees can develop a sense of value and security from their ongoing employment.

\subsection{Benefits and Incentives}

Employees should be fed, clothed, and housed as an employment benefit. Most employees in this project have suffered abject poverty; with these fundamental benefits, their attitude toward work in the project was stabilized.

Support for medical treatment should be given to employees. Although these benefits are not common HRM practices in LDCs, as with the benefits of being fed, clothed, and housed, access to medical treatment also stabilized employees' attitudes toward work. In particular, employees who utilized this benefit tended to be appreciative.

Incentive tours to more economically developed countries can significantly improve employee education and motivation. Employees who participated in incentive tours developed their hospitality skills by observing role models operating in a real business environment. Tips should be pooled and distributed equally among the employees to prevent them from misunderstanding the meaning of gratuities and to prevent troubles among the employees.

\subsection{Leadership and Teamwork}

It is a practical HRM strategy to place employees from different ethnic groups into the same divisions or workspaces, even though they have rarely worked with different ethnic groups. To manage employees based along ethnic lines disturbs an efficient HRM practice. In fact, multiethnic work group allow younger employees to communicate more openly.

It is more efficient to present promising employees with leadership opportunities through observing role models working in real business situations in more economically advanced countries than to simply provide verbal training and instructions. In fact, observational learning is a useful training method in situations where literacy is not well-established. Employees involved in fights should be punished equally and openly by management to reinforce the importance of teamwork to the project.

\section{Implications}

More than half of the Mon-Khmer ethnic families in Laos are estimated to live in poverty, with the highest rates among the four principal ethnic groups (i.e., Lao-Thai, Mon-Khmer, Chine-Tibet, and Hmong-Mien) [16]. The economic status of ethnic Mon-Khmer has strongly influenced their value system, including their attitudes toward work. In fact, no employee in the project has willingly stepped forward to be a leader. Furthermore, although employee empowerment as an HRM strategy is common in the hospitality industry of economically developed countries, employees in the project have never showed positive attitudes towards self-determination encouraged from management.

Thus, the project's HRM strategy has been adjusted to a submissive sense of value among the employees, in essence, their culture. Culture is "patterns of thinking, feeling, and acting mental programs learned throughout their lifetime" (p.4), or "software of mind" according to Hofstede's theory of national culture [17]. 
He demonstrated "software of mind" operationally by four dimensions based on results of comprehensive global studies by using factor analysis. Among those four dimensions, in particular, the dimension of power distance, which Hofstede defined as "the extent to which the less powerful members of institutions and organisations within a country expect and accept that" (p.27) [17], is assumed to be a key to understanding the above adjustment of the project's HRM strategy. Thus, this study suggested that the dimension of power distance should be considered as a critical factor developing HRM strategies to sustainably employ the indigenous poor of LDCs.

\section{Limitations of the Research and Further Studies}

An aim of this study was to propose hypothetical HRM strategies applicable for sustainable tourism employment of the poor in Southeast Asia's LDCs. However, as is the nature of a single case study, generalization of the HRM strategies suggested from this study depends on further studies of other projects.

Although this study explored HRM strategies in a privately initiated tourism project in Laos, neither the characteristics of the project initiator nor the entrepreneurship of the managing director has been explored. That may be also one of the key factors that have enabled the project to sustainably employ the poor ethnic minority people of this country thus far.

\section{Acknowledgment}

This study was supported by JSPS KAKENHI Grant Number 24611009.

\section{References}

1. United Nations, The Fourth United Nations Conference on Least Developed Countries (2011). Retrieved from http://www.un.org/en/conf/ldc/conference.html.

2. United Nations World Tourism Organization, Tourism and Least Developed Countries: a Sustainable Opportunity to Reduce Poverty (2006). Retrieved from http://www.unwto.org/sustainable/doc/tourism-and-ldc.pdf.

3. International Labour Office, Rural Development through Decent Works Stimulating Rural Growth, Jobs and Income through Tourism (2011). Retrieved from http://www.ilo.org/wcmsp5/groups/public/@ed_emp/documents/publication/wcms_161153.pdf.

4. United Nations World Tourism Organization, Tourism and Poverty Alleviation: Recommendations for Action (UNWTO, Madrid) 17-19 (2004)

5. C. Ashley, H. Goodwin, ODI Opinion, 80 (June 2007). Retrieved from http://www.odi.org/sites/odi.org.uk/files/odi-assets/publications-opinion-

files/778.pdf.

6. D. Meyer, Pro-poor Tourism -- Can Tourism Contribute to Poverty Reduction in Less Economically Developed Countries? In S. Cole, N. Morgan (Eds.), Tourism and Inequality: Problems and Prospects (CAB, London) 164-182 (2010)

7. D. Harrison, S. Schipani, Curr. Issues Tourism, 10, 194-230 (2007)

8. E. Cater, Ann. Tourism Res., 14, 202-226 (1987)

9. G. Hall, H. Patrinos, Indigenous Peoples, Poverty, and Development, (Cambridge Univ Press, Cambridge, U.K., 359-392 (2012)

10. J. Hartley (2004). Case Study Research. In C. Cassell, G. Symon (Eds.), Essential Guide to Qualitative Methods in Organizational Research (Sage, London, 323-333 (2004) 
11. R. Yin, Case Study Research Design and Methods, 4th ed. (Sage, London) 47-49 (2009)

12. V. Kitbumroong, Saensuk Pasuam Waterfalls (Available from Utayan Bajiang project) (2005)

13. M. Boella, Human Resource Management in the Hospitality Industry, 6th ed. (Stanley Thornes, Cheltenham, 1996)

14. R. Woods, Managing Hospitality Human Resources, 3rd ed. (AH\&LA, Lansing, 2002)

15. W. Suntikul, T. Bauer, H. Song, Int. J. Tourism Res. 12, 449-461 (2012)

16. A. Engvall, Ethnic minorities and rural poverty in Lao PDR, EIJS Working Paper Series (European Institute of Japanese Studies, Stockholm, 2006)

17. G. Hofstede, Culture and Organizations: Software of the mind (McGraw-Hill, London, 1991) 